\title{
Implementing H5P online interactive Activities at scale
}

\author{
Li Chen, Penelope Manwaring, Ghaith Zakaria, Sonia Wilkie, Daniel Loton \\ Victoria University
}

\begin{abstract}
Online Interactive Activities (OIA) are an increasingly popular educational learning experience. OIA allows for flexible delivery with the activities used synchronously during class, or asynchronously outside of class at a time convenient for the learner, and they prompt active participation and engagement. As a result, many learning environments are implementing design and development projects to incorporate OIA. However, incorporating new tools and approaches in educational systems can be complex. In this paper we discuss the processes that Victoria University employed to develop and implement OIA, in order to facilitate efficient blended delivery on a large scale. We discuss reasons why the tool H5P was chosen for the development of OIA; outline the projects and processes used to oversee and implement OIA roll-out; present the support mechanisms and professional development provided to enable the design, development, and incorporation of OIA; and lastly provide novel case examples to inspire future use.
\end{abstract}

Keywords: Online interactive activities; H5P; digital pedagogy; large-scale implementation; Tertiary Education

\section{Introduction}

The world in which most people live, socialise, and work is a blend that seamlessly incorporates the virtual and physical. Widespread adoption of mobile technologies (Bughin \& Chui, 2017) combined with the ubiquitous proliferation of the internet of things (Zanella et al. 2014), means people are continually and simultaneously immersed in blended experiences. These factors are also true for education systems, and the ways in which learners undertake and engage with their learning, which the COVID pandemic has amplified. Whilst many institutions were implementing programs to enable a Blended Learning experience (Rasheed, et al. (2020) provide a concise overview), COVID19 required a sudden transition from traditional modes of delivery, to hybrid and remote deliveries. Victoria University had undertaken a large-scale blended learning project commencing in 2016, which enabled a swift transition (in the space of 1 week) to remote delivery. In this paper, we present the project, how it was implemented at scale, and examples of Online Interactive Activities (OIA) as inspiration for future use.

Blended Learning combines traditional face-to-face teaching and learning activities, with online activities and resources accessed via an online learning environment. The combination of utilising technologies, multimedia resources and online interactive learning activities provides accessibility and flexibility of educational programs. This flexibility is an often-cited key reason that blended learning benefits student learning (Harahap et al., 2018; Shang \& Liu, 2018; Chen et al., 2018; Ramirez-Arellano et al., 2018; Ota, Peck, \& Porter, 2018; Cundell \& Sheepy, 2018). Meta-analyses of comparative studies estimate a small effect for blended learning on student assessment results, enhanced when synchronous learning and quizzes are prominent in the design (van Alten et al., 2019). Rankings of the most influential factors on student learning place blended learning as $52^{\text {nd }}$; although many other factors also relate to effective curriculum design that are arguably supported via blended learning (Schneider \& Preckel, 2017). It is important to note that flexibility extends from the use of different technologies, multimedia, and learning activities, to time, location, teaching and learning pace. As Chen et al. (2018), Shang and Liu (2018), and Ota et al. (2018) note, this flexibility not only enhanced learners' motivation and engagement, but also improved their self-learning, organisation and self-regulation skills. In some studies, learner satisfaction is also significantly greater for courses delivered using blended learning in place of traditional methods (Martinez-Caro et al. 2011). Güzer et al. (2014) and Baragash et al. (2018) observed that blended learning environments have a positive impact on learners' satisfaction, motivation, knowledge rate, attitude, and student retention rate. However, van Alten and colleagues' meta-analysis (2019) found no significant pooled effect of blended learning on student satisfaction, across 22 effects observed, suggesting variation in blended learning and student satisfaction. 
Learning theories provide some explanation as to why comparative empirical studies find enhanced results for blended learning over traditional models. Commonly cited theories include cognitive learning theories, constructive learning theories and media / technology theories. In traditional classroom environments, textbased or text-only resources are often heavily used, whereas multimedia instructional material is more common in blended learning environments. Multimedia based learning materials engage multiple sensory systems with rich visual and auditory information, and studies suggest incorporating video over textual resources improves outcomes (Noetel et al., 2021). Based on dual coding theory, Mayer (2002) states that visual and auditory information processing occurs in separate channels with limited capacities, and that learning is an active process to integrate new information, from different channels, into one's existing knowledge. In a blended learning environment, multimedia based learning materials help students to map the information from different types of formats to "a coherent mental representation" (Mayer, 2002), and in doing so, enables a deeper understanding (Scheiter, Schüler \& Eitel, 2017). Cognitive Load Theory is another important consideration. The theory is detailed by Sweller $(1994,2011)$ with examples of how Cognitive Load is factored into blended learning in Sithole (2019), and the design and development of OIA in Wilkie et al. (2018). A delivery that incorporates OIA via a Learning Management System (LMS) extends the space and time in which interactive teaching and learning occur. As Isaías et al. (2015) note, online learning embraces flexibility, personalised learning, and adaptive learning experiences, thereby shifting the focus to a student-centred approach. Alonso et al. (2011) recognise the importance of the design and delivery of multimedia and OIA, arguing that freedom to access these online resources motivated and encouraged learners, leading to better learning outcomes. As Dean and Lima (2017) suggest " a more flexible learning approach allows students to balance their work and study commitments".

\section{Online Interactive Activities (OIA)}

OIA are increasingly popular in education institutions and corporate training programs to introduce blended and active learning experiences (Martin et al., 2020). Active participation with interactive content has been shown to improve information retention, learning engagement, attitudes, and thinking and writing skills, over static content such as reading or watching (Prince, 2004). Furthermore, learners can engage with the OIA both synchronously and asynchronously to class time; appealing options for many institutions and learners.

A range of eAuthoring toolkits exist that enable content creators to develop OIA, such as Articulate 360, Smart Sparrow, H5P, eXeLearning, Genie, and Adobe Captivate. The activities present information in HTML5 (HyperText Markup Language version 5) - a rich media format that is enhanced with interactive clickable hotspots, quizzes, or text input prompting learners to actively participate in their learning, rather than have information passively presented at them. The functionality and attributes of OIA also leads to natural gamification of learning activities. Increasing interactivity, learner engagement and motivation are drivers for online learning design, and gamification is central to this trend (Kiesler et al., 2011). Accessible tools are also being introduced that enable educators to incorporate game-like features in learning design without going to the extent of full-scale game development which is often logistically impossible (Barata et al., 2015). However, educators face a plethora of complex technical and design-related considerations when planning or implementing a gamified strategy. Conceptual tools are emerging to help guide thinking and design choices. Toda and colleagues (2019) recently expanded a taxonomy of gamified learning into five dimensions, primarily distinguished by the learner and the learning environment. The five major dimensions are, in no particular order, Performance, Fictional, Ecological, Social and Personal elements, comprising a total of 21 game elements. These gaming elements are not mutually exclusive; gamified educational content can exhibit multiple game elements. In addition, the authors propose that game features can be either extrinsic, where they are made explicit to the end-user (usually a learner), or implicit, where their presence and purpose may not be made explicit to the end-user. As such, the functionality and attributes of OIA naturally inherits many of these gamified elements.

\section{Introducing Online Interactive Activities at Victoria University}

Generally, to maximise the utility of OIA, eAuthoring toolkits often require a high level of digital literacy, creative digital media skills, and a thorough understanding design theories, cognitive behaviour, and pedagogical practices (Wilkie et al. 2018). These factors can create barriers for those with limited technological or pedagogical skills, as well as cost implications for institutions who need to expand the workforce with specialist talent. Furthermore, many tools render the content as a SCORM (Shareable Content Object Reference Model) package which cannot be updated when needed. This poses problems for educators who need their 
information to be current, and the institution which relies on content sustainability to minimise costs.

Attempting to overcome these barriers, Victoria University sought to identify a toolkit that would be adaptable, allowing content to be easily updated, and transferable so that the content could be easily used across units, or even shareable across institutions as an Open Educational Resource (OER). Victoria University observed that $\mathrm{H} 5 \mathrm{P}$ has been effective at engaging educators in the rapid delivery of positive outcomes. H5P combines a simple and effective user interface with a variety of learning activities (content types) that allow educators easy access to a significant range of new digital formats for their legacy material. In addition, H5P encourages a collaborative community of practice that supports knowledge and skills acquisition. High-quality OIA can be created by novice users in a multitude of ways, from sourcing, cloning and modifying OIA, to designing and building unique activities from scratch with the help of simple, instructional videos.

\section{What is H5P and How is it Used?}

$\mathrm{H} 5 \mathrm{P}$ is an open source authoring toolkit that enables a user to create rich media OIA from a suite of more than 50 content types, many of which neatly align with Toda and colleagues (2019) taxonomy of gamified learning. The framework is built in a modular format so that individual activities can be assembled together, allowing for rapid and customised development. Once developed, content can be shared and incorporated into multiple OIA across a range of units, increasing sustainability. A complete and current list of content types is available at the H5P website (https://h5p.org/) however, some examples of H5P OIA used at Victoria University are outlined below.

\section{Course Presentation}

Like PowerPoint, the Course Presentation (Figure 1) presents information via a slide deck, however, interactivity can be incorporated via clickable hotspots which reveal further information, play videos, present multimedia, provide textboxes for reflection or notetaking, or allow learners to test their comprehension via quizzes.

By enabling activity types to be included within the slides, the learning experience exists in a neat, selfcontained package, which can be carefully designed to reduce learner cognitive load. To illustrate, traditional PowerPoint presentations present all information in a consecutive, linear order. The Course Presentation however, allows a single slide to contain multiple hotspots which act as anchor points, that when clicked, reveal further information. An example is shown in Figure 1. The information that was previously presented as a lengthy PowerPoint slide deck is peppered into single, information-containing anchor points on a smaller slide deck.

Figure 1. The Course Presentation content type presents information via a slide deck. It allows many activity types to be included in the tool in order engage learners through variety and to prompt interactive learning

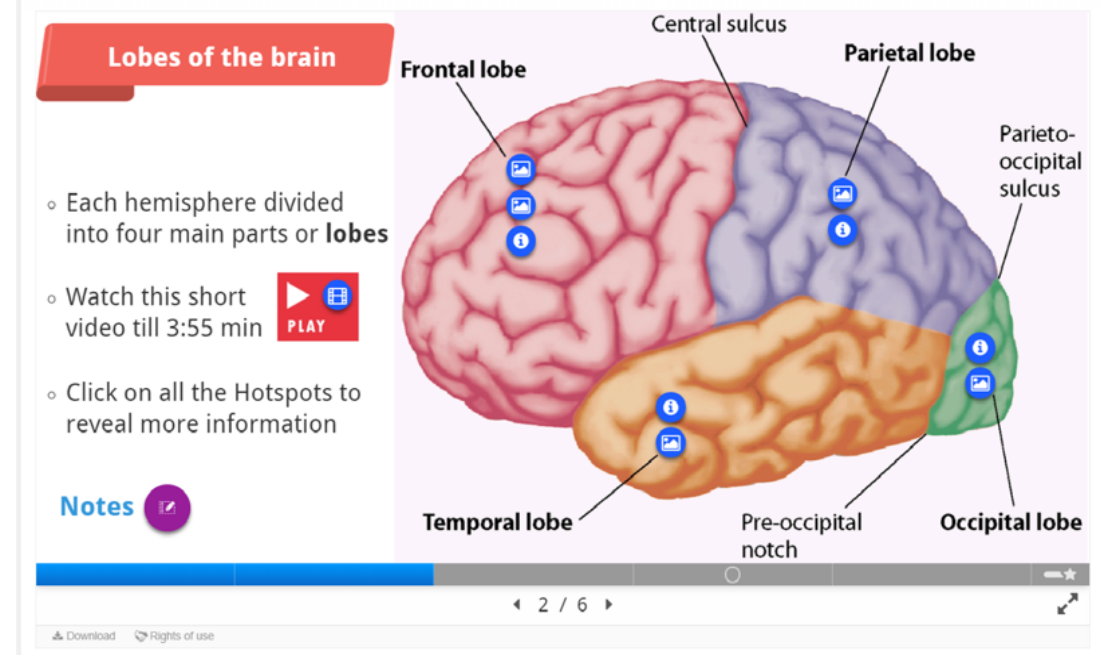

As explained by an academic "Using the course presentation tool has advantages over PowerPoint. In addition to interactive short quizzes, embedded multimedia and generally appealing professional design elements, it also enables compression of large slide decks. This is possible through the use of multiple hotspots on one single 
slide which displays the same amount of information. Furthermore, the information within each hotspot is displayed to students as a pop-up window when clicked. This is great because it doesn't scare away students as the number of slides and text displayed initially is not that substantial".

\section{Branching Scenario}

Best known as a choose-your-own-adventure activity, the Branching Scenario (Figure 2) presents learners with a scenario, followed by multiple options that (depending on the answer) will lead down different paths. The tool incorporates a range of other content types (Course Presentation, Interactive Video, Image Hotspots) allowing information to be presented with variety and novelty. The content type provides authentic learning opportunities, resembling real-life situations whereby learners are required to make decisions based on the information available. Learners can test different thinking processes as they respond to the situations differently, and progress through different outcomes. A significant, further advantage is that the Branching Scenario activity can be designed to assess learners' knowledge before diving into the learning experience, ensuring that different types of learners are equally challenged. Maintaining that all learners are equally challenged is a complex task. Novice learners can begin the learning experience at the level of introductory knowledge, whilst experienced learners can dive in where more advanced concepts are introduced. Figure 2 illustrates the decision tree for a paramedic simulation Branching Scenario whereby learners are dispatched as an ambulance response team to an emergency situation. The decision tree maps out the different activities, decisions, and paths a learner may take whilst undertaking the scenario.

\section{Figure 2. The Branching Scenario decision tree for 'The Unconscious Patient' simulation}

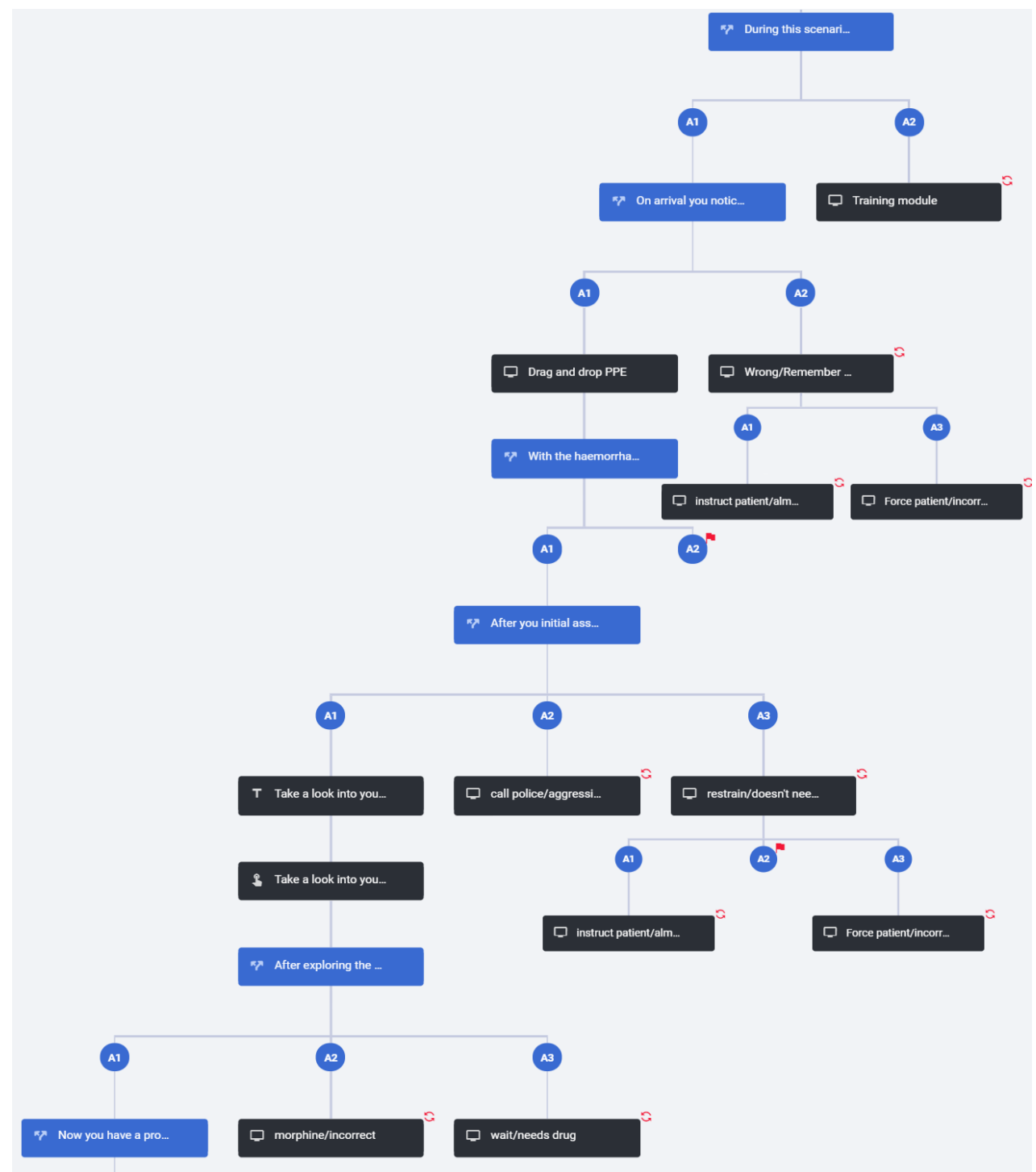




\section{Image Hotspot}

The Image Hotspot (Figure 3) is primarily used to present a diagram, with clickable hotspots extending information (text descriptions, links to websites, videos). It has the dual advantages of compressing large amounts of information into a single view, and neatly packing deeper insights into clickable hotspots.

Figure 3. The Image Hotspot Activity whereby a diagram is made interactive via clickable hotspots to reveal further information, weblinks, and multimedia

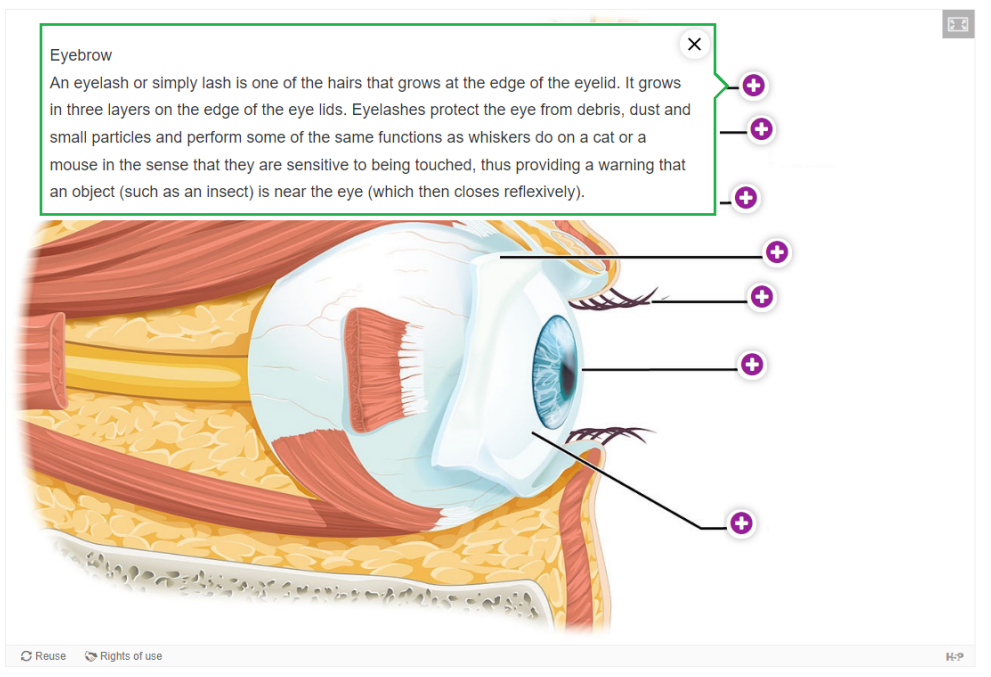

\section{Interactive Video}

The Interactive Video (Figure 4) allows users to upload or stream video content from an external host such as YouTube or an internal host such as Panopto. Learning can be extended by overlaying the video with interactive hotspots that reveal further information, diagrams, weblinks or quizzes when clicked. Additionally, the ability to stream high quality content from external sites, which is then customised and personalised by the addition of hotspots, reduces the costs associated with creating content. Previously, educators often wanted to create their own bespoke video content, however, the Interactive Video enables access to high quality, customisable content, while reducing production costs and maintaining copyright compliance. A novel use for the tool has emerged as a video annotation tool. Learners submit their video assessments as an Interactive Video, and their teacher can then annotate the videos with feedback / feedforward via time-stamped hotspots.

Figure 4. The Interactive Video allows users to upload or stream video content from external hosting sites such as Youtube, or internal hosts such as Panopto. The user can overlay the video with hotspot interactivity, that when clicked, reveal further information






\section{Virtual Tour}

The Virtual Tour (Figure 5) content types allows people to develop $360^{\circ}$ virtual tours for inaccessible locations, or for field trip preparation (Zakaria \& Wilkie, 2020). Using $360^{\circ}$ still images, interactive content can be overlaid via hotspots which are attached to items / positions in the image, and multiple images can be linked together to enable people to virtually walk through locations.

Figure 5. The Virtual tour presents $360^{\circ}$ still images that can be superimposed with interactive hotspots to display further information and can be linked to other images which allow the viewer to virtually walk through locations

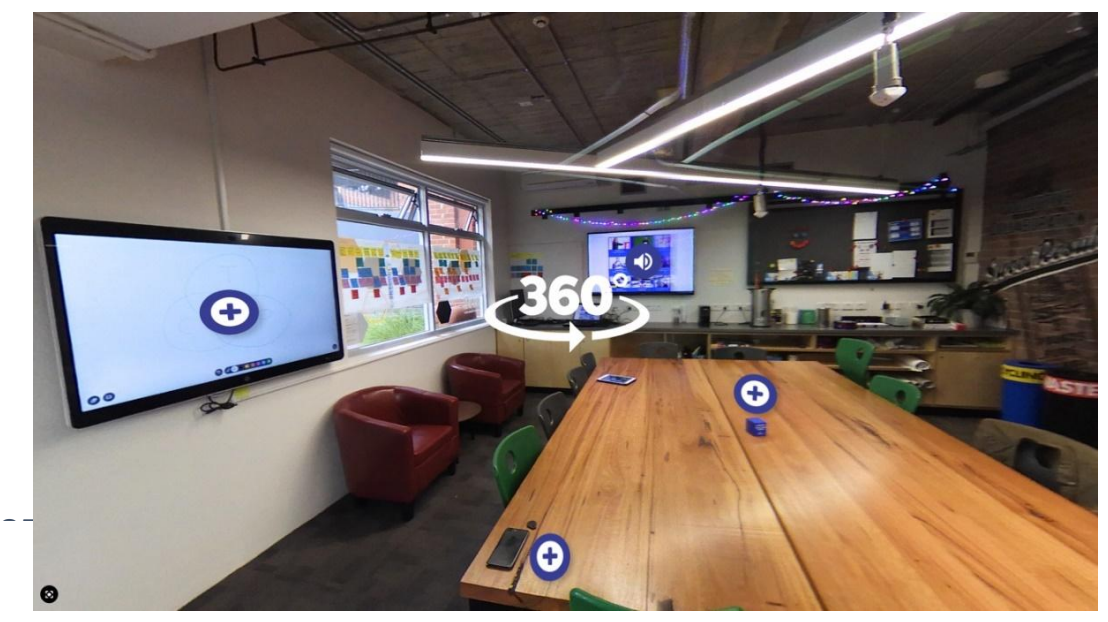

\section{Timeline}

The Timeline (Figure 6) presents information via interactive hotspots at key points over time. The hotspots present images, multimedia, text, and weblinks to external information. Whilst primarily used to present historical information over time, an unexpected and novel application for the content type involves using it as a unit guide, presenting key information about topics, important activities to undertake, readings, assessments, and when they occur during the unit's delivery. This application of the content type bridges the use from an activity with content delivery, to administrative functionality.

Figure 6. The Timeline content type employed as a unit guide.

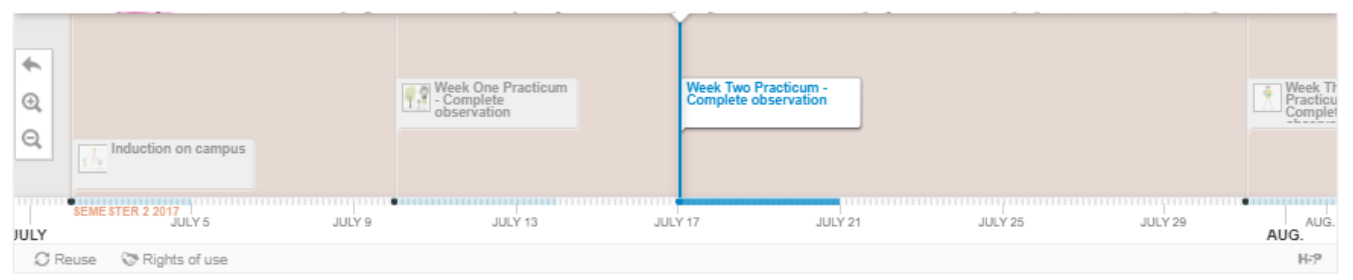

\section{Projects to Implement Online Interactive Activities at Scale}

Victoria University introduced H5P in 2014 as a part of a pilot program to implement blended learning across the university and increase staff digital literacy skills. Anecdotally, early adopters found the toolkit to be user friendly, and others with moderate digital literacy skills found it easy to use. Furthermore, the toolkit included a range of suitable content types that enabled a broad range of activities well suited to the tertiary level curriculum and expectations. This meant that educators could easily conceive of applications for the OIA that were consistent with their existing pedagogical practices, which as Ertmer (2005) and Koehler and Mishra (2009) propose, are key factors for the initial adoption of any new pedagogical practice.

In mid-2016, the university formally launched the 'Blended Learning Project' with the aim of implementing a blended learning delivery at scale. It initially incorporated 112 units and increased in scale in 2017 with the University's Block Model curriculum redesign project. This project commenced with all first-year units and was 
further extended to encompass every course (and unit) across the university by 2021. A summary of the Block Model principles by McCluskey et al. (2019) is provided below:

- Incorporating Active, Blended, and Student-centred learning strategies and experiences

- Incorporating authentic learning experiences and assessments

- Early and ongoing feedback / feedforward, with assessments distributed early and across the delivery

- Ensuring that the unit is ready to deliver with all content, activities, assessment information, rubrics, and resources provided on the LMS for learners to view one week before teaching commences.

These curriculum design projects, which were driven by a top-down approach with senior leadership and uppermanagement leading the projects, were key for engaging all teaching and support staff across the university. Crucially, in regards to the diffusion of innovation (Rogers, 2010; Sahin, 2006) this approach engaged not just the early adopters or early majority, but also the laggards who were least motivated to participate. These curriculum design projects were also key to developing the OIA to a quality standard. Information about good design principles to consider when developing OIA is provided by Wilkie, Zakaria, McDonald and Borland (2018). To summarise, the key design principles include management of cognitive load, incorporating active learning tasks, scaffolding in prompts for learner self-reflection and knowledge checks at key points, maximising opportunities to engage the learners by presenting the information in a variety of methods and modalities, designing elements to reduce mind wandering, and segmenting the content into bite-sized portions (chunks). The chunking of content into bite-sized portions is particularly important for the OIA, as it not only increases sustainability of the activities (smaller topic specific activities are more likely to be cloned, adapted, and incorporated into a range of subjects), but also enables learners to undertake their learning with minimal distraction from external factors. For example, learning can occur during free moments, on a commute, or during a lunch break. Furthermore, a greater proportion (if not all) of a chunked learning activity could be completed without the distraction of email notifications, phone calls, messages, and conversations. Having completed a learning activity, the learner feels rewarded, making it easier to progress on to the next portion, rather than trying to find the exact location in a larger learning module to resume their learning before another distraction arises, and reward for completion is delayed.

\section{Building Capacity}

To build staff capacity it was important to recognise that staff required a broad understanding of TPaCK (Koehler \& Mishra, 2009) and that a program of support, tailored and accessible to the individual users, would need to be developed. As Koehler and Mishra note "Many approaches to professional development offer a onesize-fits-all approach to technology integration when, in fact, teachers operate in diverse contexts of teaching and learning" (p. 62, 2009). To ensure success, the professional development strategy required the following aspects. Namely, that teaching staff recognise the benefits of adopting a blended learning teaching strategy, and understand both how to pedagogically incorporate OIA into the curriculum and their teaching practice, and how to technically design and develop OIA. The Connected Learning Team provided support and training via the following methods:

- Weekly meetings with learning designers and design teams for staff engaged in the curriculum redesign and development phase of projects (The Blended Learning Project and The Block Model).

- Scheduled professional development workshops for both large and small groups of staff.

- One-to-one professional development sessions.

- Just-in-time support via a drop-in centre operating during business hours (9am-5pm, Monday- Friday).

- A LiveChat online messaging tool for instant assistance or referral to a professional development session.

- Online user guides and screencasts demonstrating step-by-step processes for development.

- University-wide shared practice forums providing opportunities for staff to showcase their activities, demonstrate how they were incorporated in the curriculum, and comment on their effectiveness.

- Hosting an international conference (H5P Con, 2018) to inspire staff as well as providing an opportunity for staff to showcase their work at an elite level.

- A case studies online space exampling high quality and novel use of learning activities.

- Assisted development whereby students-as-staff and learning designers developed the activities on behalf of the staff to incorporate or further customise. 
This structured support which became Business-As-Usual ensured that assistance, encouragement, and inspiration was readily available and accessible no matter the time, location, or duration required. The process which is further detailed by Borland et al. (2019) and Forbes et al. (2019), ensured that designed activities were based on a foundation incorporating Technological, Pedagogical, and Content Knowledge considerations (TPaCK).

\section{How online interactive activities were Incorporated}

The curriculum design projects were key to establishing a process for educators and design teams to appropriately design and implement OIA. This ensured that the OIA were scaffolded into the unit as learning activities during the unit design process, rather than ad-hoc afterthought (see unit design mapping in Figure 7). This approach enabled educators and design teams to conceptualise the appropriate OIA and its relationship to and alignment with other learning activities, to scaffold its placement in the delivery timeline, and to consider how it was to be undertaken (as a pre-class, in-class, or post-class activity).

Figure 7. Mapping out the learning activities during the unit design stage



\section{Scaffolding Pre-class / Post-class Activities}

Setting the expectation that students undertake learning outside of class time is often a difficult task for many educators. Examples of typical pre- and post-class learning activities include reading textbooks and watching video recordings. However, the incorporation of LMS-accessible OIA expands the possibilities for active learning opportunities such as quizzing at key milestones for learner self-assessment, and embedded text input boxes that prompt and scaffold written preparation or reflection tasks. At Victoria University, this capability has led to innovative approaches such as $360^{\circ}$ virtual tours of locations to prepare learners for field trips and site visits (Zakaria \& Wilkie, 2020), and branching scenario simulations that provide learners with opportunities to test different thought processes through decision making.

The flipped classroom model, whereby students undertake theoretical learning activities outside of class-time then discuss the concepts or apply their skills during class time, is increasingly employed at many institutions, proving to be popular and effective at engaging students with their own learning (Dean \& Lima, 2017; Lee, Lim, $\& \mathrm{Kim}, 2017)$, and is now characteristic of many units at Victoria University. Covid19 work-from-home restrictions emphasised the need to optimise time spent on campus with practical activities, and theoretical learning being undertaken remotely. The OIA were easily conceptualised to fit into this delivery strategy as preclass activities, guiding people through learning, and allowing them to spend as much time as needed on theoretical knowledge, which could then be consolidated and applied during the class under the watchful eye of the instructor. 


\section{In-class Activities}

Traditionally, the LMS online space has been underutilised, acting as a document repository and tool for assessment submission. In seeking to blur the boundaries between in-class and face-to-face activities, and those undertaken online, the blended learning strategy has incorporated OIA into class time through:

- Information presentation (using Course Presentation) enabling learners to interact with slides, engage in active learning such as note taking, and self-quiz to gauge their comprehension.

- Structured writing activities (using Documentation Tool) that scaffold instructions and prompts to assist with writing methods, formats and conventions. The skill of report writing is one such example.

- Other activities that test theoretical knowledge and understanding, such as Drag-and-Drop, Branching Scenario simulations, and virtual tours.

\section{Group Activities}

Whilst OIA offer great opportunities for students to learn, interact, engage, and gauge their understanding of concepts via embedded quizzes and interactive activities, they are often undertaken at an individual level, with limited capacity for group participation or multiplayer competition. Group activities can utilise gamification techniques to provide opportunities to conduct collaborative or team-based learning in multiple formats, as well as in both physical and virtual learning environments. Collaborative learning requires interaction, discussion and debate to occur both amongst learners, and between the educator and learners. Panitz (1999) notes that learners need to develop higher level thinking skills, social skills and communication skills in a collaborative learning environment. Students are able to recall their forgotten knowledge by collaborating with others, and reduce the recall errors that they made during study by receiving feedback from peers and instructors (Panitz, 1999). Instead of knowledge transmission, Wang and $\mathrm{Mu}$ (2017) considered collaborative learning as "an active process of knowledge construction". Within a blended learning environment, students have the opportunity to construct their knowledge by interacting with their peers and instructors. Rahman (2017) believed that students learned better by taking interactive learning activities and receiving feedback from both peers and instructors during the learning process. Musabirov, Pozdniakov and Tenisheva's work (2019) confirmed that the connections and interactions between peers had significant impacts on learners' achievement. Similarly, Cundell and Sheepy (2018) found that well-structured learning activities provided students with opportunities to see and analyse the work of others.

Audience Response Tools, also known as Online Polling Tools, are web-based platforms with an onlineinterface (app/webpage) compelling users (students) to vote for answers to questions, and collate responses into visual representations such as charts or images. Popular examples include Socrative, Poll Everywhere, Kahoot and Mentimeter. These activities have been found to increase students in-class engagement, participation, tendency to express views, and comfort at doing so, leading to improvement in overall learning experience (Gauci et al., 2009; Rose, 2019; Lim, 2017; Ismail, et al., 2019). The online polling activities intrinsically motivate learners and create a more enjoyable in-class experience (Kim, 2020), and are an important method for educators to engage learners who may be shy, introverted, or simply uncomfortable speaking in front of their peers (Medaille \& Janet 2011). In addition, learners from non-English speaking backgrounds can lack confidence due to the language barrier, and become disengaged as a result (Crose, 2011). A learner's silence in the classroom has the potential to be perceived as a sign of disengagement and misinterpreted by educators or fellow learners (Medaille \& Janet 2011). This factor alone is of considerable importance for Victoria University, as it has one of the highest percentages of learners from non-English speaking backgrounds in Australia (McCluskey et al., 2019). These tools also offer insightful metrics, metadata, heat map measurements and flags that assist educators to identify learners who are struggling with their studies, and then help to inform the design of future learning resources (Sclater et al., 2016; Siemens \& Long, 2011). Whilst these third-party online platforms offer a range of free and paid polling activities that can be deployed in blended learning environments, a number of concerns arise with the use of commercial tools. This includes the requisite for high-level digital literacy skills deeming them challenging for educators to create and implement; the distraction of operating across multiple platforms rather than within one, and LMS integration obstacles. Furthermore, maintaining confidentiality and data security for learners poses a concern for universities. Third-party tools are often hosted in external servers with unknown cybersecurity measures and policies regarding collection, use, and selling of users' data. Learners often access these platforms via personal computers, mobile phones and computers, meaning that learners are unwittingly granting these platforms access to confidential personal information (such as names, numbers, contact details, locations, etc.), posing data security and duty of care concerns for the universities and learners on-par. Victoria University collaborated with H5P to eliminate these disadvantages by developing a Multiplayer suite of tools that includes polling-like activities (Word Cloud, Emoji Cloud, Multipoll) that enable group-work, collaboration and gamification. The multiplayer platform inherits H5P's 
advantages of being hosted on a secure AWS server in Sydney, capable of integration into the LMS, tool familiarity which reduces user learning curve, and boosts learners' engagement and interactivity with the curriculum.

\section{Summary}

This paper presents the processes, methods and examples of the broad types of OIA that Victoria University deployed to both enable a blended delivery and increase staff digital literacy skills at scale. Overall, results suggest a successful and steady implementation of a new technology, and learning and teaching activity, that was a key goal of several unique, but overlapping, teaching and learning enhancement projects. The examples of activities shown reflect the range and diversity of content types that were most regularly used, and suitable for our dual sector environment.

Anecdotally, staff have given generally positive feedback regarding the usability and suitability of the OIA. Librarian Sarika Singh mentions a number of benefits "The use of the H5P tool has been adopted by the library and has provided significant benefits. For instance, having the H5P content embedded into a unit space not only increased the visibility and accessibility of the resources but also placed the learning content at learners' point of need. Sharing of the OIA through the H5P repository has further positioned the library to be able to promote information and digital literacy learning materials to the teaching academics who can reuse as well as customize the OIA to suit their student cohorts".

The feedback from staff also includes suggestions for future development, both technically and pedagogically in order to enhance the use of OIA, learning activities, and opportunities for a blended learning delivery. The Branching Scenario, Emoji Cloud, Word Cloud, Multipoll, and The Chase were such requests that led to the development of a new content types. To rise to these requests, Victoria University collaborates with H5P and our LMS provider D2L (Desire to Learn) to develop these content types as learning activities for all.

\section{Thank you}

Thank you Trish McCluskey, Mike Sturmey, the Connected Learning Team, Victoria University staff and students (https://vucollaboratehelp.vu.edu.au/about-us/meet-the-team).

\section{References}

Baragash, R. S., \& Al-Samarraie, H. (2018). Blended learning: Investigating the influence of engagement in multiple learning delivery modes on students' performance. Telematics and Informatics, 35(7), 2082-2098. https://doi.org/10.1016/i.tele.2018.07.010

Barata, G., Gama, S., Jorge, J., \& Gonçalves, D. (2015). Gamification for smarter learning: Tales from the trenches. Smart Learning Environments, 2(1), 10. https://doi.org/10.1186/s40561-015-0017-8

Borland, R., McDonald, T., Zakaria, G., \& Wilkie, S. (2019). Engaging staff with program redesign and blended learning in two large scale institutional projects. The Higher Education and Technology Agenda Conference (THETA) Proceedings. Wollongong, Australia.

Bughin, J., \& Chui, M. (2017). The Internet of Things: Assessing its potential and identifying the enablers needed to capture the opportunity. The Internet of Things in the Modern Business Environment. IGI Global. https://doi:10.4018/978-1-5225-2104-4.ch006

Chen, J., Lu, H., Zhou, H., \& Zhou, Y. (2018). Study on blended learning under background of emerging Engineering Education. Proceedings of the 9th International Conference on Information Technology in Medicine and Education (ITME), 610.

Crose, B. (2011). Internationalization of the higher education classroom: Strategies to facilitate intercultural learning and academic success. International Journal of Teaching and Learning in Higher Education, 23(3), 388-395. https://eric.ed.gov/?id=EJ946165

Cundell, A., \& Sheepy, E. (2018). Student perceptions of the most effective and engaging online learning activities in a blended graduate seminar. Online Learning, 22(3), 87-102. https://doi.org/10.24059/olj.v22i3.1467

Dean, A., \& Lima, A. (2017). Student Experience of E-Learning Tools in HE: An integrated learning framework. European Journal of Social Sciences Education and Research, 11(2), 39-51. http://journals.euser.org/files/articles/ejser_sep_dec 17 nr_2/Aftab.pdf

Ertmer, P. A. (2005). Teacher pedagogical beliefs: The final frontier in our quest for technology integration?. Educational technology research and development, 53(4), 25-39. https://doi.org/10.1007/bf02504683 
Forbes, L., Zakaria, G., and Wilkie, S. (2019). Partnerships for Design. Collaborative Curriculum: Design and Delivery. In the proceedings of the Tertiary Education Quality and Standards Agency (TEQSA), Melbourne, Australia.

Gauci, S. A., Dantas, A. M., Williams, D. A., \& Kemm, R. E. (2009). Promoting student-centered active learning in lectures with a personal response system. Advances in Physiology Education, 33(1), 60-71.

Güzer, B., \& Caner, H. (2014). The Past, Present and Future of Blended Learning: An in Depth Analysis of Literature. Procedia - Social and Behavioral Sciences, 116, 4596-4603. https://doi.org/10.1016/j.sbspro. 2014.01.992

Harahap, D., Hurriyati, R., Gaffar, V., \& Amanah, D. (2018). The impact of word of mouth and university reputation on student decision to study at university. Management Science Letters, 8(6), 649-658. https://doi.org/10.5267/j.msl.2018.4.027

H5P Conference 2018, (accessed Oct 1, 2021). https://h5pcon-2018.h5p.org/

Isaías P., Spector J., Ifenthaler D., Sampson D. (2015). E-Learning Systems, Environments and Approaches: Theory and Implementation. In E-Learning Systems, Environments and Approaches. Springer.

Ismail, I., Elihami, E., \& Mustakim, M. (2019). Students' Perceptions of the Benefits of Mobile Polling Technology in Teaching and Learning in College: Implications of Students' Participation and academic Performance. Jurnal Pendidikan Progresif, 9(1), 89-104. https://doi.org/10.23960/jpp.v9.i1.201912

Kiesler, S., Kraut, R. E., Koedinger, K. R., Aleven, V., \& Mclaren, B. M. (2011). Gamification in education: What, how, why bother. Academic Exchange Quarterly, 15(2), 1-5.

Kim, Y. (2020). The Value of Interactive Polling and Intrinsic Motivation When Using English as a Medium of Instruction. Sustainability, 12(4), 1332. https://doi.org/10.3390/su12041332

Koehler, M., \& Mishra, P. (2009). What is technological pedagogical content knowledge (TPACK)?. Contemporary Issues in Technology and Teacher Education, 9(1), 60-70. https://www.jstor.org/stable/24636917

Lee, J., Lim, C., \& Kim, H. (2017). Development of an instructional design model for flipped learning in higher education. Educational Technology Research and Development, 65(2), 427-453. https://doi.org/10.1007/s11423-016-9502-1

Lim, W. N. (2017). Improving student engagement in higher education through mobile-based interactive teaching model using socrative. In IEEE Global Engineering Education Conference (EDUCON). https://doi.org/10.1109/EDUCON.2017.7942879

Mayer, R. E. (2002). Multimedia learning. Psychology of Learning and Motivation, 41(1). 85-139. https://doi.org/10.1016/S0079-7421(02)80005-6

MacKenzie, L., \& Ballard, K. (2015). Can Using Individual Online Interactive Activities Enhance Exam Results. Journal of Online Learning and Teaching, 11(2), 262-266. https://jolt.merlot.org/Vol11no2/Ballard_0615.pdf

Martin, F., Sun, T., \& Westine, C. D. (2020). A systematic review of research on online teaching and learning from 2009 to 2018. Computers \& education, 159, 104009. https://doi.org/10.1016/j.compedu.2020.104009

Martínez-Caro, E., \& Campuzano-Bolarín, F. (2011). Factors affecting students' satisfaction in engineering disciplines: traditional vs. blended approaches. European Journal of Engineering Education, 36(5), 473-483. https://doi.org/10.1080/03043797.2011.619647

Medaille, A., \& Usinger, J. (2019). Engaging Quiet Students in the College Classroom. College Teaching, 67(2), 130-137. http://dx.doi.org/10.1080/87567555.2019.1579701

McCluskey, T., Weldon, J., \& Smallridge, A. (2019). Rebuilding the first year experience, one block at a time. Student Success, 10(1), 1-16. https://doi.org/10.5204/ssj.v10i1.1148

Noetel, M., Griffith, S., Delaney, O., Sanders, T., Parker, P., del Pozo Cruz, B., \& Lonsdale, C. (2021). Video improves learning in higher education: A systematic review. Review of Educational Research, 91(2), 204236. https://journals.sagepub.com/doi/abs/10.3102/ 0034654321990713

Ota, M., Peck, B., \& Porter, J. (n.d.). Evaluating a Blended Online Learning Model Among Undergraduate Nursing Students: A Quantitative Study. CIN - Computers Informatics Nursing, 36(10), 507 - 512. https://doi.org/10.1097/CIN.0000000000000456

Prince, M. (2004). Does Active Learning Work? A Review of the Research. Journal of Engineering Education, 93(3), 223-231. https://doi.org/10.1002/j.2168-9830.2004.tb00809

Ramirez-Arellano, A., Acosta-Gonzaga, E., Bory-Reyes, J., \& Hernandez-Simon, L. M. (2018). Factors affecting student learning performance: A causal model in higher blended education. Journal of Computer Assisted Learning, (6), 807.

Rasheed, R. A., Kamsin, A., \& Abdullah, N. A. (2020). Challenges in the online component of blended learning: A systematic review. Computers \& Education, 144, 103701.

https://doi.org/10.1016/j.compedu.2019.103701 
Rogers, E. M. (2010). Diffusion of innovations. Simon and Schuster. pp.1-38.

Rose, S. (2019). Exploring the Impact of In-Class Polling Tools on Student Engagement in Higher Education. Technology and the Curriculum: Summer 2019. https://techandcurr2019.pressbooks.com/ chapter/polling-tools-and-engagement/

Sahin, I. (2006). Detailed review of Rogers' diffusion of innovations theory and educational technology-related studies based on Rogers' theory. Turkish Online Journal of Educational Technology-TOJET, 5(2), 14-23. http://tojet.net/articles/v5i2/523.pdf

Schneider, M., \& Preckel, F. (2017). Variables associated with achievement in higher education: A systematic review of meta-analyzes. Psychological Bulletin, 143(6), 565.

Scheiter, K., Schüler, A., \& Eitel, A. (2017). Learning from multimedia: Cognitive processes and instructional support. In The Psychology of Digital Learning (pp. 1-19). Springer, Cham. https://link.springer.com/chapter/10.1007/978-3-319-49077-9_1

Shang, F., \& Liu, C.-Y. (2018). Blended learning in medical physiology improves nursing students' study efficiency. Advances In Physiology Education, 42(4), 711-717. https://doi.org/10.1152/advan.00021.2018

Sclater, N., Peasgood, A., \& Mullan, J. (2016). Learning analytics in higher education. London: Jisc. Accessed February, 8(2017), 176. https://www.jisc.ac.uk/sites/default/files/learning-analytics-in-he-v3.pdf

Siemens, G., \& Long, P. (2011). Penetrating the fog: Analytics in learning and education. EDUCAUSE Review, 46(5), 30. https://eric.ed.gov/?id=EJ950794

Singh, H. (2003). Building effective blended learning programs. Educational Technology-Saddle Brook Then Englewood Cliffs NJ-, 43(6), 51-54.https://eric.ed.gov/?id=EJ679022

Singh, S., \& Scholz, K. (2017). Using an e-authoring tool (H5P) to support blended learning: Librarians' experience. Facilitating social learning through learning design: A perspective of collaborative academic development, 158. https://2017conference.ascilite.org/wp-content/uploads/2017/11/Concise-SINGH.pdf

Sithole, S. T. (2019). Enhancing blended learning materials using cognitive load theory. Journal of Modern Accounting and Auditing, 15(1).

Sweller, J. (1994). Cognitive load theory, learning difficulty, and instructional design. Learning and instruction (4, 295-312). https://doi.org/ 10.1016/0959-4752(94)90003-5

Sweller, J. (2011). Cognitive load theory. In Psychology of learning and motivation (55, 37-76) Academic Press. https://doi.org/10.1016/B978-0-12-387691-1.00002-8

Toda, A.M., Klock, A.C.T., \& Oliveira, W. et al. (2019). Analysing gamification elements in educational environments using an existing Gamification taxonomy. Smart Learning Environments, 6(1), 16. https://doi.org/10.1186/s40561-019-0106-1

van Alten, D. C., Phielix, C., Janssen, J., \& Kester, L. (2019). Effects of flipping the classroom on learning outcomes and satisfaction: A meta-analysis. Educational Research Review, 28, 100281. https://doi.org/10.1016/j.edurev.2019.05.003

Wilkie, S., Zakaria, G., McDonald, T., \& Borland, R. (2018). "Considerations for designing H5P online interactive activities". Open Oceans: Learning without borders. Proceedings ASCILITE, 543-549.

Wilkie, S., Zakaria, G., \& McDonald, T. (2018). Transforming Lectures to (H5P) Online Interactive Activities. The. Higher Education Research and Development Society of Australasia.

Zakaria, G., Wilkie, S. 2020. Applications for virtual reality experiences in tertiary education. In ASCILITE's First Virtual Conference. Proceedings ASCILITE, 186-193.

Zanella, A., Bui, N., Castellani, A., Vangelista, L., \& Zorzi, M. (2014). Internet of things for smart cities. IEEE Internet of Things Journal, 1(1), 22-32. https://doi.org/10.1109/JIOT.2014.2306328

Chen, L., Manwaring, P., Zakaria, G., Wilkie, S., Lotan, D. (2021). Implementing H5P online interactive activities at scale. In Gregory, S., Warburton, S., \& Schier, M. (Eds.), Back to the Future - ASCILITE '21.

Proceedings ASCILITE 2021 in Armidale (pp. 81-92). https://doi.org/10.14742/ascilite2021.0112

Note: All published papers are refereed, having undergone a double-blind peer-review process.

The author(s) assign a Creative Commons by attribution licence enabling others to distribute, remix, tweak, and build upon their work, even commercially, as long as credit is given to the author(s) for the original creation.

(C) Chen, L., Manwaring, P., Zakaria, G., Wilkie, S., Lotan, D. 2021 